\title{
Information Security in Education: Are We Continually Improving?
}

\author{
Dennis Bialaszewski \\ Indiana State University, Terre Haute, IN, USA
}

Dennis.Bialaszewski@gmail.com

\begin{abstract}
This paper will shed light on the lack of the development of appropriate monitoring systems in the field of education. Test banks can be easily purchased. Smart phones can take and share pictures of exams. A video of an exam given through Blackboard can easily be made. A survey to determine the extent of cheating using technology was given to several university students. Evidence is provided that shows security is lacking as evidenced by the number of students who have made use of technological advances to cheat on exams. The findings and conclusion may serve as evidence for administrators and policy makers to re-assess efforts being made to increase security in online testing.
\end{abstract}

Keywords: education, security, testing, cheating, monitoring

\section{Introduction}

Technology has contributed to the rapid growth of the offering of online courses in education. In a presentation made by Tim Berners-Lee, at a TED Talks conference (Berners-Lee, 2014), offered that now 1 in 3 higher education students take at least one online course every semester.

Technological advances have been rapidly taking place and will continue to do so. W Edwards Deming posits that training is essential to Total Quality Management (TQM) but is the training to those involved in the field of education sufficient, and are sufficient systems being developed to safeguard information that is being used to assess student achievement? There are situations where I have firsthand knowledge that there are sufficient precautions but I also have evidence that we in the field of education are falling woefully short.

It was my great honor to have been recruited by the EDUCATIONAL TESTING SERVICE (ETS) - College Board to serve on a three to four person committee with the responsibility for constructing and selecting questions to be used on the College Level Examination Program (CLEP) exam in the field of Information Systems. I consider it an honor as ETS must have felt

Material published as part of this publication, either on-line or in print, is copyrighted by the Informing Science Institute. Permission to make digital or paper copy of part or all of these works for personal or classroom use is granted without fee provided that the copies are not made or distributed for profit or commercial advantage AND that copies 1) bear this notice in full and 2) give the full citation on the first page. It is permissible to abstract these works so long as credit is given. To copy in all other cases or to republish or to post on a server or to redistribute to lists requires specific permission and payment of a fee. Contact Publisher@InformingScience.org to request redistribution permission. that I had sufficient expertise in the area but also felt that my ethical practices were acceptable, as I would have access to questions and answers appearing on exams, and I would do all that I could possibly do in order to safeguard the security of the CLEP questions. Although our committee met occasionally in person at the ETS campus in Princeton, New Jersey, we often communicated via email. Through email we sug- 
gested questions and answers and commented on questions and answers that others submitted. However, we used data encryption of all material that was sent. There was a need for public and private keys to decrypt the questions that were sent. The encryption program we used was Pretty Good Privacy (PGP) from PGP Corporation. However, in 2010 Symantec Corporation acquired PGP for 300 million dollars.

I learned the importance of statistical testing of potential answers as the "wrong" answers must not be answers that nobody without knowledge of the topic would select, but answers that someone with inadequate knowledge of the topic might mistakenly select. Taking part in this process, as I served under contract for three years, made me quite aware of the deficiencies of many of the existing multiple-choice questions that are sometimes included in test banks and coupled with textbooks. A team of statisticians for ETS did rigorous pretesting of suggested questions to insure the reliability and validity of each question and set of answers before they could be selected to appear on the actual version of the CLEP exam in Information Systems. Yet too often, because of large class sizes, objective multiple-choice exams are given and software such as Blackboard is promoted in order to assess students in large classes. This process may lead to even larger classes where security may become an even bigger issue. There is a faculty member who is my colleague and who is teaching more than 400 students this semester, with one class having more than 200 students. We do not have a doctoral program and there is no Teaching Assistant. He is forced to rely on multiple-choice tests with automated grading.

In this research I will present cases that provide evidence that security has been breached a number of times in the field of education to justify that there is a need to study this topic based on past experiences. Then the prevalence of existing data banks will be discussed. Sources will be given where many test banks can currently be purchased which provide answers to questions that are used from test banks. And many faculty members use test banks as creating and testing their own questions taking into consideration the pretesting them for reliability and validity of each question would be an arduous task which might also necessitate the teaming with a statisticians to complete the process. The following section will present the structuring of a survey that was randomly distributed to a sample of 497 students in a Midwest university along with the empirical results. Lastly, a summary and conclusion of our findings will be provided along with suggestions for changes that are necessary in our educational system if we are to truly legitimize the assessing of our students in our technologically advancing work.

\section{Evidence of the Need for Security}

There have been many instances of successful breaches of educational data used for assessment of individuals, and with advancing technology one can safely assume there will be more such attempted. There have been attempts made at the state, national, and international levels and we will list only a few of these attempts to support the need for continual improvement in security in the field of education. At the state level there have been issues with the scores of the ISTEP (Indiana Statewide Testing for Educational Progress) exam. In one case there were erasures in a third grade math class, which were questionable as 121 of the 125 answers were changed from wrong to right ("ISTEP breaches spur closer look," 2011). There actually was an eighth grade essay question posted on Facebook. The DOE stated that an essay question was posted verbatim on Facebook and via email while students were still taking the exam. This ISTEP breach invalidated 83,000 test scores ("New ISTEP security breach," 2011). Technology such as email and social media was not considered sufficiently in developing a security system.

After arrests were made of students from Long Island High Schools in 2011 changes were made in the process of taking SAT and ACT exams (Anderson, 2012). Students who had been arrested were paid as much as $\$ 3,600$ to take the exam for another student. Students from 5 high schools were charged. One of the students arrested said that he took tests for both males and females if 
they had a gender neutral name. Kathleen Steinberg, the Executive Director of the College Board, stated that of 3,000 scores that were questioned there were 1,000 scores canceled and another 750 scores dismissed for various infractions such as having a cell phone in the testing center. Prior to 2011 students did not have to have their scores reported to their high schools. New procedures now allow for the test results to be sent to all high schools along with a picture of the test taker. Security breaches can happen at all levels of schools including ivy league colleges as there was a report of cheating by as many as 125 students at Harvard. (Perez-Pena \& Bidgood, 2012)

Breaches of security can happen in any country and can impact an entire country as was done in South Korea. In May of 2013 The College Board and ETS made the difficult but necessary decision to cancel the SAT and subject specific SAT exams at all testing centers in the Republic of Korea (Rivers, 2013). This action resulted after the Educational Testing Service/ College Board learned that many of the tutoring centers (Hakwons) there had illegally obtained SAT materials for their own commercial benefit. This information was provided to the ETS - the College Boards vendor for global administration and security by the Supreme Prosecuting Office.

Breaches have occurred with information to assess student achievement in an organization that certainly has the resources to devote a great deal of money to safeguard information. It has been reported that the College Board has reported yearly revenue of more than 750 million dollars. And yet breaches occur (Meserve, 2014). With this being the case, how much can colleges and universities budget for security in information to assess student achievement?

\section{Test Banks are Easily Available}

With higher operating costs, costs for insuring faculty, and so forth for colleges and universities and revenues from the state sometimes being restrained, the universities are finding the process of setting budgets becoming filled with even more difficult decisions. There are pressures to minimize tuition increases and, thus, decisions to be made about possible cuts. This is leading to larger class sizes in some universities. In the university that I currently teach in class sizes are increasing, and there are many who propose that faculty resort to more objective testing that can be automatically graded and that software such as Blackboard be used. It also is my personal experience that it is not always easy to prosecute someone who cheats as the burden of proof is on the faculty member and then various boards to make decisions and mete out penalties. When I have reported an incidence of cheating I was once asked "what percent of the course grade was that test?" In my response I stated that if we were a "service school" it would not have mattered much as to the percent of the course grade. To which I received a response of "we are not a service school." It seems there either is a fear of lawsuits arising from penalizing students or an incentive to retain students or some other reason to not take cheating as seriously as I believe we once did. With advancing technologies and shared data students now have much easier access to test banks than they did in the past. More than 40 years ago I knew of a student who was given an actual printed test bank that was used for constructing exams in a course. So trying to obtain test banks is certainly not a new phenomenon. However, the ease of buying and selling them made possible through advancements in technology certainly is. But yet there is reliance and these test banks as the questions are believed to be reliable and valid (although they have not always been statistically tested) and with class sizes of 200 and no graduate assistants it is not easy to always construct and grade newly created essay questions that promote creative thinking.

I do have firsthand knowledge of faculty just succumbing to the system and feeling rewarded by doing so. I have heard faculty justify doing so in a conversation with me. I was told that they do not mind the large class and that they will just use the automated tests and use the Blackboard software. When I brought to the attention of the faculty member that students can buy the test bank for the course the response I got was at least they will go through those questions and learn that material. It was an answer that was hard for me to digest. But just how easy are test banks 
and study guides with solutions to obtain? An internet search reveals many sources in just a matter of minutes. And this does not include all of the banks that can be shared via Facebook or some other social media system or even via a simple email attachment. Fifty years ago I would have thought it was wrong to have a test bank of any kind in my possession. However, since it is being viewed as good study practice it is being widely advertised as such. The following are the results of a search obtained in minutes on Sunday - October $5^{\text {th }}, 2014$, at about 2:00 PM.

I placed the words "test bank" and performed a Google Search. An advertisement was listed first for Koofers. The URL given was https://www.koofers.com/testbank. Some of the statements made on the Koofers site are:

Free Test Banks

Student governments, fraternities, sororities, and academic organizations have been organizing test banks for decades. Koofers has simplified the system, brought the offline practice online, and provides free and equal access to test banks to all college students. Search for a particular exam or set of exams from both past and present semesters.

and

\section{Past Exams, Old Tests, and Study Guides}

Our extensive library of old exams and shared class notes allows you to effectively study for class and prepare for exams. Study practice exams; review lecture notes and study guides. Study old tests, quiz questions, notes, and study guides from your class, professor and university, or from students in equivalent courses nationwide.

The next advertisement that was posted was from ustestbank. The URL given is http://ustestbank.com/

Figure 1 shows the graphic at the top of their site.

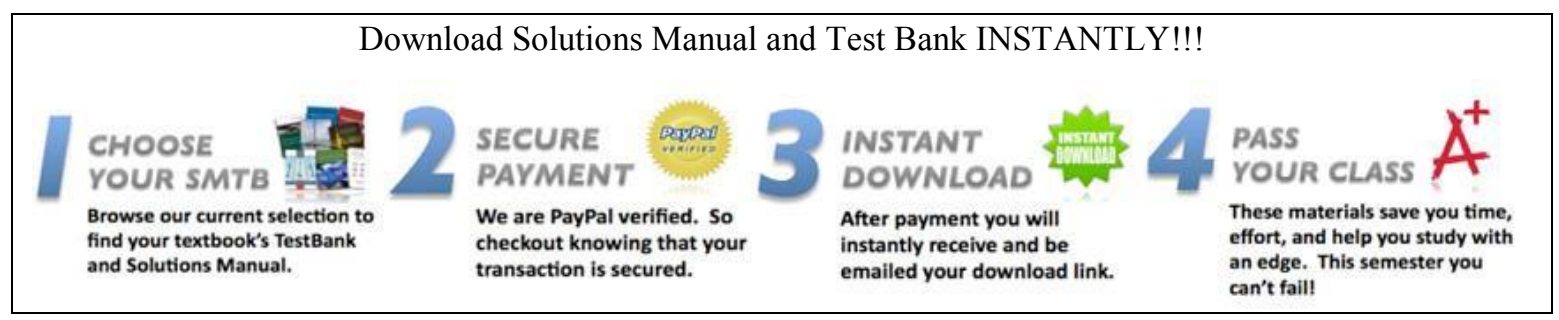

Figure 1. Graphic from ustestbank

And you will see specific subject ads such as "Test Bank for Medical-Surgical Nursing, 7th Edition: Donna D. Ignatavicius Download.”

Given that it is the $7^{\text {th }}$ edition you know that this text along with a test bank must have been used multiple times. And it is almost a certainty that a completely new test bank was not developed each time. This one source had 3,777 listings when I last checked the site with listing 3,777 being "Zoology $8^{\text {th }}$ Edition; Stephen Miller Test Bank."

The third URL was also an advertisement and it was for testbank.org. The URL was: http://www.testbank.org/

Their Home Page states:

We have more than 5 years of experiences of helping students getting better insights for their classes. With those solid experience and great customer service, TestBank.org strives to deliver the best quality materials to our customers. If you are looking for a test bank or a solution manual for your academic textbook then you are in the right place. 
Test Bank Store provides test banks and solution manuals for college students and instructors. We have helped a lot of students from top notch colleges and universities, including Harvard, Princeton, Yale, and Stanford.

and

Benefits of Test Banks / Exam Banks

Purchasing a Test Bank / Exam Bank is the best value-for-money tool that you will enjoy aside from various benefits that you can get. The primary benefit of a test bank or exam bank is that you will gain insight on the subject matter you are studying. With this benefit, you will be able to avoid mistakes on your exams. You will be able to focus on the topics that you are studying. Other than gaining more knowledge, you can customize your studying methods with the use of test bank. With these tools, you won't experience any difficulties when you're studying because you will be able to concentrate on the subject where you think you need an improvement. So, if you don't want to fail on your next exam, consider purchasing TB because this can make the difference.

And of course they list a multitude of available study test banks.

Of course there are several more sources that the readers can check out for themselves. The sites listed above are advertisements listed using a Google search and are listed in these positions as they were the highest bidders using Google's adwords for advertising. This is an ever popular advertising technique as Google made nearly 42 billion dollars in advertising in 2012 .

It is also interesting to note that on Monday $10 / 6 / 14$, as I was writing this article, a used book buyer knocked on my door. He was interested in purchasing used books but he was also interested in purchasing instructor's copies of texts, which contain answers to the text questions. Even though there is a move towards etexts (Bialaszewski, 2013) he stated that he was with a start-up company and thought the future would be bright for the next couple of years as there would be demands for instructor's editions.

\section{Methodology - Survey and Results}

A survey instrument was created and pretested to study student attitudes towards cheating. This instrument collected data on demographics, such as gender, class standing, and living on or off campus. Twenty attitudinal questions were constructed using a 5 point Likert Scale where respondent were to provide an attitude from 1 equaling strongly agreeing to 5 signifying strongly disagreeing. Students were selected randomly and in total there were 497 respondents. However, not all students answered all questions. The survey was distributed at a Midwest University with a student body greater than 12,000 .

For the purpose of this research we will focus only on relevant technology related questions. The following attitudinal statements were listed and students responded using the scale described above:

1. I believe technology advances have made it easier to cheat.

2. I know of a student who has used their phone to take a picture of an exam.

3. I believe there is more cheating in Distance Education courses than in classes offered in a classroom.

4. I have helped a student cheat on Blackboard administered tests.

Four hundred ninety four (494) of the 497 respondents answered the question related to believing that technology made it easier for them to cheat. The results are given in Table 1. 
Table 1. Student opinions concerning the statement, "I believe technology advance have made it easier to cheat."

\begin{tabular}{|l|l|}
\hline Descriptor: & Frequency: \\
\hline 1= Strongly Agree & 262 \\
\hline 2= Agree & 121 \\
\hline 3= Neutral & 74 \\
\hline 4= Disagree & 17 \\
\hline 5= Strongly Disagree & 20 \\
\hline
\end{tabular}

Thus an extremely large percent of students believe that technology does make cheating easier. Constructing $95 \%$ confidence intervals we find that we are $95 \%$ confident that $68 \%+/-4.8$ of all students believe that technology has made it easier to cheat. When comparing gender we obtained the results in Table 2.

\begin{tabular}{|l|l|l|l|}
\hline \multicolumn{4}{|c|}{ Table 2. Gender specific data concerning the statement, } \\
"I believe technology advance have made it easier to cheat." \\
\hline Descriptor & Frequency (males) & Descriptor & Frequency (females) \\
\hline 1= Strongly Agree & 141 & 1= Strongly Agree & 121 \\
\hline 2= Agree & 59 & 2= Agree & 62 \\
\hline 3= Neutral & 33 & 3= Neutral & 41 \\
\hline 4= Disagree & 10 & 4= Disagree & 7 \\
\hline 5= Strongly Disagree & 10 & 5= Strongly Disagree & 10 \\
\hline
\end{tabular}

In testing for a difference in attitude by gender we obtain a p-value of .407 and thus there is no significant difference in attitude by gender when it comes to agreeing that technology has made it easier to cheat.

The next statement we look at is whether there is agreement with the statement "I know of a person who has used their phone to take a picture of an exam." We find the following:

Our estimated population proportion is $46 \%$ with a Margin of Error of $4.5 \%$. That is, we estimate the population percentage for that university where students knew of phones being used to take a picture of an exam is at least $40.5 \%$ to at most $50.5 \%$ with $95 \%$ confidence. We will again examine if there is a difference by gender using the data in Table 3.

\begin{tabular}{|l|l|l|l|}
\hline \multicolumn{4}{|c|}{ Table 3. Gender specific data concerning the statement, } \\
\hline Descriptor & Frequency (males) & Descriptor & Frequency (females) \\
\hline 1= Strongly Agree & 68 & 1= Strongly Agree & 56 \\
\hline 2= Agree & 49 & 2= Agree & 53 \\
\hline 3= Neutral & 29 & 3= Neutral & 23 \\
\hline 4= Disagree & 34 & 4= Disagree & 38 \\
\hline 5= Strongly Disagree & 73 & 5= Strongly Disagree & 71 \\
\hline
\end{tabular}

When testing for difference in gender versus no difference in attitude by gender we obtain a $p$ value of .740 and thus there is no support for a statistical difference in gender. 
We next examine the attitude regarding a belief that there is more cheating taking place in distance education courses as opposed to in classroom courses. We find the attitudes regarding this statement in Table 4.

\begin{tabular}{|l|l|}
\hline \multicolumn{2}{|c|}{$\begin{array}{c}\text { Table 4. Data concerning the statement, "I believe there is more cheating } \\
\text { in Distance Education courses than in classes offered in a classroom." }\end{array}$} \\
\hline Descriptor & Frequency \\
\hline 1= Strongly Agree & 156 \\
\hline 2= Agree & 111 \\
\hline 3= Neutral & 127 \\
\hline 4= Disagree & 60 \\
\hline 5= Strongly Disagree & 39 \\
\hline
\end{tabular}

One of the respondents opted not to answer this question. We again constructed a $95 \%$ confidence interval and obtained an estimate that $54 \%$ of the student population believe that there is more cheating taking place in distance education courses. The Margin of Error was determined to be $4.5 \%$ and thus we believe that at least $49.5 \%$ to at most $58.5 \%$ of the students believe that there is more cheating taking place in distance education courses. We again examine for a statistical difference by gender. We find the results in Table 5 .

Table 5. Gender specific data concerning the statement, "I believe there is more cheating in Distance Education courses than in classes offered in a classroom."

\begin{tabular}{|l|l|l|l|}
\hline Descriptor & Frequency (males) & Descriptor & Frequency (females) \\
\hline 1= Strongly Agree & 84 & 1= Strongly Agree & 71 \\
\hline 2= Agree & 67 & 2= Agree & 44 \\
\hline 3= Neutral & 51 & 3= Neutral & 76 \\
\hline 4= Disagree & 27 & 4= Disagree & 33 \\
\hline 5= Strongly Disagree & 22 & 5= Strongly Disagree & 17 \\
\hline
\end{tabular}

One male respondent did not answer this question. $60.3 \%$ of the male respondents believe that there is more cheating taking place in distance education courses while 47.7 percent of the females believe there is more cheating taking place in distance education courses. Testing for a statistically significant difference we find a $\mathrm{p}$ value of .005 and thus strong support for a statistical difference when comparing gender. This was an unexpected result and determining factors will be left for future research. However, what is certain is that there is a meaningful percentage of students who do believe that there is more cheating taking place during distance offered courses. This begs the question to re-examine the monitoring systems that have been put in place in order to minimize cheating.

In all cases if there are few penalties for being caught cheating this may also lead to a faculty member being a little more lax when structuring or applying an existing monitoring system. As he/she may feel there is added work but not real benefit to it. However, this would need to be tested and is left for future research in this area.

Although there were several other survey questions, most are beyond the primary emphasis of this paper. The last question we examine is the admittance to actually helping someone cheat on a 
blackboard administered exam. Three of the respondents opted not to answer the question regarding helping a friend cheat on a Blackboard exam. We obtained the results in Table 6:

\begin{tabular}{|l|l|}
\hline \multicolumn{2}{|c|}{ Table 6. Data concerning the statement, } \\
"I have helped a student cheat on Blackboard administered tests." \\
\hline Descriptor & Frequency \\
\hline 1= Strongly Agree & 119 \\
\hline 2= Agree & 113 \\
\hline 3= Neutral & 77 \\
\hline 4= Disagree & 54 \\
\hline 5= Strongly Disagree & 128 \\
\hline
\end{tabular}

Thus 232 students out of 491 who responded to the question agreed, to some degree, that they did help a friend cheat on a Blackboard exam. That is $47.3 \%$ if the sample admitted to helping a friend cheat. Constructing a 95\% confidence interval we find that we are $95 \%$ confident that at least $43 \%$ of the student population to at most $52 \%$ of that universities population stated that in some way they have helped a friend cheat on a Blackboard exam. Viewing this question in a different manner and realizing that 77 students were non-committal on this question we find that only 182 of the respondent stated that they did not help a friend cheat. Constructing a $95 \%$ C.I. we estimate that only $37.1 \%$ did not help a friend cheat on this type of exam with the Margin of error being $2.2 \%$.

I do not believe that this university is much different than many other universities. However, I understand that further research needs to be completed to support that claim. However, these results are presented as a caution to university administrators and political leaders in the state who support larger class sizes and more automated exams using multiple-choice exams. How can one help cheat on a blackboard exam? There are many ways, but if cell phones are not monitored in a testing setting it would be a simple matter to take a video of exams even if question order is being generated randomly and then to set up a data base of possible questions for an exam given at a later date. On the survey it was only asked if pictures of exams were taken it was not asked whether a video of an exam was taken and that is a weakness of this study.

Comparing results using gender we obtained the results in Table 7.

\begin{tabular}{|l|l|l|l|}
\hline \multicolumn{4}{|c}{ Table 7. Gender specific data concerning the statement, } \\
"I have helped a student cheat on Blackboard administered tests." \\
\hline Descriptor & Frequency (males) & Descriptor & Frequency (females) \\
\hline 1= Strongly Agree & 63 & 1= Strongly Agree & 56 \\
\hline 2= Agree & 58 & 2= Agree & 55 \\
\hline 3= Neutral & 37 & $3=$ Neutral & 40 \\
\hline 4= Disagree & 25 & 4= Disagree & 29 \\
\hline 5= Strongly Disagree & 67 & 5= Strongly Disagree & 61 \\
\hline
\end{tabular}


Thus 121 males $(63+58)$ out of 250 male respondents agreed that they helped a friend cheat on a Blackboard exam while 111 females out of the 241 female respondents agreed. We again tested for a statistically significant difference in gender. We obtained a p-value of .651 and thus there is no statistical evidence that one gender is more prone to cheat on a blackboard exam than the other gender.

\section{Concluding Remarks and Future Direction}

Distance education courses can be extremely useful. I am not attempting to present a case against Distance Education. I was the first faculty member to offer a course in $\mathrm{C}++$ programming as a traditional course at an introductory level for our university. However, I basically self taught myself the subject matter by using existing tutorials with a distance type format and then developed a course delivered in a somewhat similar way to other programming courses that I had taught. The issue that I am attempting to bring up for study is the need for appropriate monitoring of all courses and in particular for distance education courses. Perhaps test centers need to be set up. Without appropriate monitoring the integrity of the assessment may certainly be questioned. These sorts of things need to be factored in when budgeting for courses offered in a distance format. And what role should faculty play in this monitoring system and possibly setting up satellite testing sites? Should there be a centralized structure in a university to set up such testing sites? What are the policies at the university regarding cheating? Is cheating being taken quite lightly, as it appears to be by students at this university? Could it be because there are few real penalties applied? Are we so worried about retention that we spend our efforts in that area and do not devote sufficient time to promoting students to act at all times with integrity so that they will be better prepared for being true contributors to society?

Furthermore, are current faculty being trained properly in technology and is it being promoted in a positive way to faculty? Are there incentives to promote all faculty keeping up with technology? Is this knowledge being demanded, ignored, or actually part of a plan to prepare faculty to continue to offer the best education possible? I actually have spoken to faculty who were unaware of the numerous sites existing where students can easily purchase text banks with all questions and answers to both test sets and study guides. What is worse is that I have spoken to a faculty member who says he does not care because he is being rewarded by offering courses with large sections and can only do so by using all multiple choice exams. He follows that up by saying, "Well if they study those questions they at least can answer those questions." But that loses site of creative thinking and obtaining a deeper understanding of course content. Allowing students to do this certainly does not make them good citizens.

As a final statement I encourage the reader to bring these issues up for discussion in your institutions. I encourage your administrators to encourage and discuss this with your state policy makers who wish to increase class sizes, retain more students, lower costs with larger classes, and automate the entire testing process. Please make them aware that there are considerations that must be considered and factored into the budget in order to assess properly. It is true that if the employers are not satisfied with the quality of our students they will hire students from other institutions. If our students do not have appropriate backgrounds with good writing and analytical skills the employers who interview them will not hire them. Whatever structure and policy we design, we should not lose site of the first point in W. Edwards Deming's list of 14 points for Total Quality Management, that being, to always keep our long run purpose in mind. Our long run purpose as educators should be to offer a high quality education that enables our students to become good members of society. Implicit in this is that students obtain the proper tools and skills to become employable. 


\section{References}

Anderson, J. (2012, March 27). SAT and ACT to tighten rules after cheating scandal. The New York Times. Retrieved 10/7/2014 from http://www.nytimes.com/2012/03/28/education/after-cheating-scandal-satand-act-will-tighten-security.html?pagewanted=all

Berners-Lee, T. (2014). Tim Berners-Lee: A Magna Carta for the web. Retrieved from https://www.youtube.com/watch?v=rCplocVemjo

Bialaszewski, D. (2013). Student attitudes regarding ebooks: A survey with cost savings implications Journal of Systemics, Cybernetics and Informatics, 11(5), 76-79. Retrieved from http://www.iiisci.org/journal/sci/FullText.asp?var=\&id=IEA569VZ

ISTEP breaches spur closer look at testing. (2011, June 4). Indianapolis Business Journal. Retrieved 10/7/2014 from http://www.ibj.com/istep-breaches-spur-closer-look-at-testing/PARAMS/article/27572

Meserve, J. (2014, March 7). Were SAT changes for the kids or to help the college board make more money? The Motley Fool. Retrieved 10/7/14 from http://www.fool.com/investing/general/2014/03/07/howthe-sat-changes-will-help-the-college-board-ma.aspx

New ISTEP security breach invalidates 83,000 test scores. (2011, March 10). WTHR.com. Retrieved 10/6/2014 from http://www.wthr.com/story/14225485/new-istep-security-breach-invalidates-83000test-scores

Pérez-Peña, R., \& Bidgood, J. (2012, August 30). Harvard says 125 students may have cheated on a final exam. The New York Times. Retrieved 10/7/2014 from http://www.nytimes.com/2012/08/31/education/harvard-says-125-students-may-have-cheated-onexam.html? r $=0$

Rivers, D. (2013). South Korea cheating scandal hits university bids. CNN. Retrieved on 10/6/2014 from http://www.cnn.com/2013/05/09/world/asia/south-korea-exam-scandal

\section{Biography}

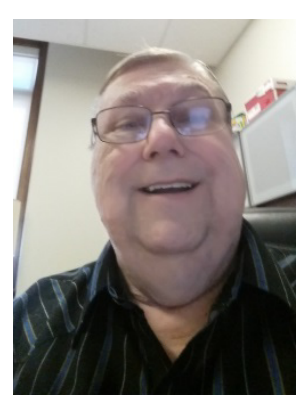

Dr. Bialaszewski has had more than 90 presentations and publications. He is the author of Information Systems for the Future - 2nd Edition and is currently writing an Introduction to Google drive with Applications,. He has received the New York State Chancellor's Award for Excellence in Teaching, he has received the Professional Productivity Award from Indiana State University, and an award for Exemplary Service to Indiana State University. He had served on many doctoral committees while at Mississippi State University and served as a Department Chair for ten years at Indiana State University.

An early grant he received allowed him to construct the first state of the art computer lab at Indiana State University. He served as the President of the International Academy for Information Management (now known as SIG-ED AIS) and currently serves as the Director of Alpha Iota $\mathrm{Mu}$ - http://alphaiotamu.org/ $\mathrm{He}$ is active in many other professional and community organizations. 